\title{
Optical properties of C-doped bulk GaN wafers grown by halide vapor phase epitaxy
}

Sergey Khromov, Carl Hemmingsson, Bo Monemar, Lars Hultman and Galia Pozina

\section{Linköping University Post Print}

\section{Tweet}

N.B.: When citing this work, cite the original article.

Original Publication:

Sergey Khromov, Carl Hemmingsson, Bo Monemar, Lars Hultman and Galia Pozina, Optical properties of C-doped bulk GaN wafers grown by halide vapor phase epitaxy, 2014, Journal of Applied Physics, (116), 22, 223503.

http://dx.doi.org/10.1063/1.4903819

Copyright: American Institute of Physics (AIP) http://www.aip.org/

Postprint available at: Linköping University Electronic Press

http://urn.kb.se/resolve?urn=urn:nbn:se:liu:diva-113340 


\section{AIP tameded}

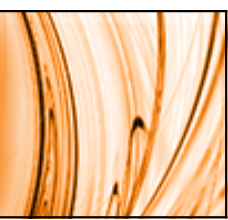

Optical properties of C-doped bulk GaN wafers grown by halide vapor phase epitaxy

S. Khromov, C. Hemmingsson, B. Monemar, L. Hultman, and G. Pozina

Citation: Journal of Applied Physics 116, 223503 (2014); doi: 10.1063/1.4903819

View online: http://dx.doi.org/10.1063/1.4903819

View Table of Contents: http://scitation.aip.org/content/aip/journal/jap/116/22?ver=pdfcov

Published by the AIP Publishing

\section{Articles you may be interested in}

Correlation between Si doping and stacking fault related luminescence in homoepitaxial m-plane GaN

Appl. Phys. Lett. 103, 192101 (2013); 10.1063/1.4828820

Optical and structural studies of homoepitaxially grown m-plane GaN

Appl. Phys. Lett. 100, 172108 (2012); 10.1063/1.4706258

Strain-free bulk-like GaN grown by hydride-vapor-phase-epitaxy on two-step epitaxial lateral overgrown GaN template

J. Appl. Phys. 96, 799 (2004); 10.1063/1.1753073

Optical spectroscopy of $\mathrm{GaN}$ grown by metalorganic vapor phase epitaxy using indium surfactant

Appl. Phys. Lett. 76, 3388 (2000); 10.1063/1.126655

Contribution of free-electron recombination to the luminescence spectra of thick GaN films grown by hydride vapor phase epitaxy

J. Appl. Phys. 85, 7888 (1999); 10.1063/1.370602

\section{SHIMADZU Powerful, Multi-functional UV-Vis-NIR and Excellence in Science FTIR Spectrophotometers}

Providing the utmost in sensitivity, accuracy and resolution for applications in materials characterization and nano research

- Photovoltaics - Ceramics

- Polymers - DNA film structures

- Thin films - Coatings

- Paints - Packaging materials
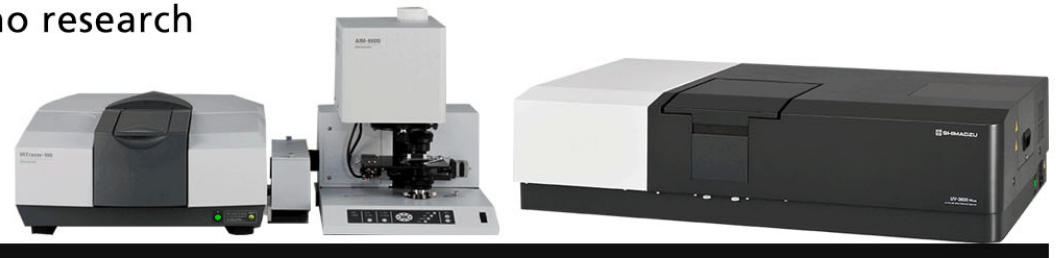


\title{
Optical properties of C-doped bulk GaN wafers grown by halide vapor phase epitaxy
}

\author{
S. Khromov, C. Hemmingsson, B. Monemar, L. Hultman, and G. Pozina \\ Department of Physics, Chemistry, and Biology (IFM), Linköping University, S-581 83 Linköping, Sweden
}

(Received 13 October 2014; accepted 23 November 2014; published online 10 December 2014)

\begin{abstract}
Freestanding bulk C-doped GaN wafers grown by halide vapor phase epitaxy are studied by optical spectroscopy and electron microscopy. Significant changes of the near band gap (NBG) emission as well as an enhancement of yellow luminescence have been found with increasing $\mathrm{C}$ doping from $5 \times 10^{16} \mathrm{~cm}^{-3}$ to $6 \times 10^{17} \mathrm{~cm}^{-3}$. Cathodoluminescence mapping reveals hexagonal domain structures (pits) with high oxygen concentrations formed during the growth. NBG emission within the pits even at high $\mathrm{C}$ concentration is dominated by a rather broad line at $\sim 3.47 \mathrm{eV}$ typical for $n$-type $\mathrm{GaN}$. In the area without pits, quenching of the donor bound exciton (DBE) spectrum at moderate $\mathrm{C}$ doping levels of $1-2 \times 10^{17} \mathrm{~cm}^{-3}$ is observed along with the appearance of two acceptor bound exciton lines typical for Mg-doped GaN. The DBE ionization due to local electric fields in compensated GaN may explain the transformation of the NBG emission. (C) 2014 AIP Publishing LLC.
\end{abstract}

[http://dx.doi.org/10.1063/1.4903819]

\section{INTRODUCTION}

Since further development of efficient GaN-based electronic and optoelectronic devices requires homoepitaxial growth, there is a strong need to manufacture $\mathrm{GaN}$ substrates with different types of doping. For example, low resistive $\mathrm{GaN}$ wafers are necessary for such applications as laser diodes and light emitting diodes (LEDs), while semi-insulating (SI) $\mathrm{GaN}$ substrates are demanded for high power microwave and high electron mobility transistor (HEMT) structures.

Carbon, due to its valence-electron configuration, upon substitution acts as an acceptor on $\mathrm{N}$ site or a donor on the $\mathrm{Ga}$ site. From theoretical calculations, the formation energy for substituting $\mathrm{Ga}$ for $\mathrm{C}$ is much higher than for the $\mathrm{C}_{\mathrm{N}}$ configuration, thus, $\mathrm{C}$ more favorably substitutes $\mathrm{N}$ in intentionally C-doped $\mathrm{GaN}$ for both Ga-rich or N-rich growth conditions. ${ }^{1}$ Achieving $p$-type material for $\mathrm{GaN}$-based optoelectronic devices by C-doping proved to be difficult so far. Highly resistive layers, however, can be obtained by doping $\mathrm{GaN}$ with $\mathrm{C}^{2}{ }^{2}$ These layers are used as back-barrier for high voltage operation to suppress drain leakage currents. ${ }^{3}$ The high resistivity is suggested to be obtained by different mechanisms: through compensation of residual $n$-type impurities ( $\mathrm{Si}$ or $\mathrm{O}$ ) by carbon acceptor atoms, ${ }^{4}$ by compensating acceptor $\mathrm{C}_{\mathrm{N}}$ with donor $\mathrm{C}_{\mathrm{Ga}}$ (Ref. 2), or by compensation of $\mathrm{C}_{\mathrm{N}}$ with interstitial $\mathrm{C}_{\mathrm{I}}$ when the Fermi level is close to the midgap. ${ }^{1}$

There is still no agreement about the position of the $\mathrm{C}_{\mathrm{N}}$ acceptor atom in the $\mathrm{GaN}$ bandgap. In early papers, $\mathrm{C}_{\mathrm{N}}$ was assumed to be a shallow acceptor, ${ }^{1,5}$ at the same time $C_{I}$ was found to be a deep donor. However, recent theoretical calculations by Lyons et al. ${ }^{6}$ show that $\mathrm{C}_{\mathrm{N}}$ is a deep acceptor, while $C_{I}$ was found to have a high formation energy and unlikely to be formed.

Special interest is drawn to a defect-related luminescence band, the so-called yellow band luminescence (YL), which is centered at $2.2 \mathrm{eV}$. It is considered undesirable as it limits the overall efficiency of the optoelectronic devices. The nature of YL is still under discussion and it was explained by $\mathrm{C}$ impurities ${ }^{7,8}$ by the presence of $\mathrm{V}_{\mathrm{Ga}}$ (Ref. 9) or threading dislocations. ${ }^{10}$ A number of researchers attribute it to a $\mathrm{V}_{\mathrm{Ga}}-\mathrm{O}_{\mathrm{N}}$ complex. ${ }^{11-14}$ Rather, most of these mechanisms may be present at the same time; however, at higher $\mathrm{C}$ doping, a higher energy band appears in the spectrum. ${ }^{8}$

Fabrication of large area GaN substrates with a relatively low concentration of impurities (still barely available) has so far been done by halide vapor phase epitaxy (HVPE). ${ }^{15-17}$ Unintentionally doped HVPE GaN has a moderate concentration of the residual donors (i.e., silicon and oxygen) of $\sim 10^{17} \mathrm{~cm}^{-3}$. ${ }^{15}$ Silane $\left(\mathrm{SiH}_{4}\right)$ has been successfully used to control the $n$-type doping level in the range of $10^{17}-10^{18} \mathrm{~cm}^{-3} \cdot{ }^{18}$ To obtain SI, GaN material iron has been used as a suitable dopant. Fe can substitute Ga upon which it acts as a compensating deep acceptor. ${ }^{19}$ However, during the growth of HEMT structures, Fe from the GaN:Fe substrates can incorporate into the GaN epilayer making the sheet resistance worse and, thus, affecting device operation. ${ }^{20}$ On the other hand, carbon can be a promising alternative dopant for fabrication of SI bulk GaN substrates by the HVPE method, following an example of successful use of $\mathrm{C}$ in metal-organic vapor phase epitaxy (MOVPE) growth of SI GaN layers for HEMT structures. ${ }^{21}$ Previously, it was found that doping by $\mathrm{C}$ during the HVPE growth of GaN results in increase of $\mathrm{YL}$ around $2.2 \mathrm{eV}^{22}$

In this work, we have studied a number of free-standing bulk GaN substrates doped by $\mathrm{C}$ with different concentrations. Although, a significant effect of C-doping on structural and luminescence properties of HVPE GaN has been observed, we here mainly focus on the excitonic emission. We have found that increasing carbon concentration up to moderate values $\left(1-2 \times 10^{17} \mathrm{~cm}^{-3}\right)$ results in transformation of the near band gap (NBG) spectrum typical for n-type $\mathrm{GaN}$ into the luminescence reported for the $\mathrm{Mg}$-doped $\mathrm{GaN}$ layers. 


\section{EXPERIMENTAL}

The growth of bulk ( $>2 \mathrm{~mm}$ thick) $\mathrm{GaN}$ samples was done in a vertical HVPE reactor at $\sim 1000{ }^{\circ} \mathrm{C}$ at atmospheric pressure on $2 \mu \mathrm{m}$ thick GaN templates grown by MOCVD on 2-in. (0001) $\mathrm{Al}_{2} \mathrm{O}_{3}$ wafers. Details about the HVPE process parameters can be found in Refs. 16 and 23. Acetylene gas (1000 ppm of $\mathrm{C}_{2} \mathrm{H}_{2}$ diluted in $\mathrm{N}_{2}$ ) was used as a source of carbon doping in the range of $\sim 10^{16}$ (undoped GaN) $-6 \times 10^{17}$ $\mathrm{cm}^{-3}$. Doping concentrations were measured using secondary ion mass spectrometry (SIMS). In all samples concentrations of $\mathrm{Mg}, \mathrm{Fe}$ and other metals were below the detection limit. $\mathrm{Si}$ concentration was $\sim 10^{16} \mathrm{~cm}^{-3}$ and constant for all samples. The average oxygen concentration was $\sim 10^{19} \mathrm{~cm}^{-3}$ independent of $\mathrm{C}$ concentrations, however it is non-uniformly distributed. Areas with so-called hexagonal pits (will be discussed below) have $\mathrm{O}$ concentration of $\sim 10^{19} \mathrm{~cm}^{-3}$, while the material without pits has a much lower $\mathrm{O}$ concentration of $\sim 3-5 \times 10^{16} \mathrm{~cm}^{-3}$. Even undoped HVPE GaN bulk samples with such hexagonal pits have an average $\mathrm{O}$ concentration of $\sim 10^{19} \mathrm{~cm}^{-3}$. We still cannot avoid the pits in our process, which however, allows us to produce large area bulk $\mathrm{GaN}$ wafers without cracking. In this case, the sapphire is partly self-separated from GaN after growth and can be removed by lapping. The front face of the $\mathrm{GaN}$ substrates has been polished. Electrical measurements (IV) have shown that $\mathrm{GaN}$ doped by carbon within the aforementioned concentrations is still conductive, though such measurements have only indicative character due to small cracks in material and surface defects mainly introduced by polishing. Transmission electron microscopy (TEM) imaging was done with a high resolution FEI Tecnai G2 $200 \mathrm{keV}$ FEG microscope. Crosssectional TEM samples were prepared by a conventional technique, including mechanical polishing to $70 \mu \mathrm{m}$ thickness and subsequent ion-milling in Ar plasma to several nanometers to be electron transparent. Photoluminescence (PL) and time-resolved PL (TRPL) were studied using an excitation by the third harmonics $\left(\lambda_{\mathrm{e}}=266 \mathrm{~nm}\right)$ from a Ti:sapphire femtosecond pulsed laser with a frequency of $75 \mathrm{MHz}$. The laser power density with the spot size used was about $100 \mathrm{~W} / \mathrm{cm}^{2}$. A Hamamatsu syncroscan streak camera with a temporal resolution of $\sim 20 \mathrm{ps}$ was used for detection of the TRPL signal. Cathodoluminescence (CL) measurements were done using a MonoCL4 system integrated with a FEG cathode LEO 1550 Gemini scanning electron microscope (SEM) and equipped with a cold-stage for temperaturedependent experiments in the range $5-300 \mathrm{~K}$. A CCD detector and a Peltier-cooled GaAs photomultiplier tube were used for data acquisition. To avoid an undesirable contribution of the near-surface defects caused by polishing, the CL spectra were measured with an accelerating voltage of $20 \mathrm{kV}$ then the penetration depth of electrons exceeds $\sim 1 \mu \mathrm{m}$.

\section{RESULTS AND DISCUSSION}

The studied thick (1-2 mm) bulk GaN substrates grown by HVPE have a low threading dislocation density of $\sim 10^{6} \mathrm{~cm}^{-2} .{ }^{17}$ However, the surface in our as-grown samples is usually rough and has to be polished before optical investigations. Thus, different structural defects can be introduced near the surface due to such treatment. Stacking faults (SFs) in the undoped $\mathrm{GaN}$ substrates can be formed to a depth of $\sim 20-30 \mathrm{~nm}$ as confirmed by TEM measurements on the present samples (not shown). It is found that this type of defects occurs more easily during polishing if the samples were intentionally doped with carbon. Fig. 1 illustrates typical examples of structural imperfections observed by TEM for the studied GaN:C samples. The arrow in Fig. 1 indicates the growth orientation [0001]. Besides threading dislocations, dislocation loops (Fig. 1(a)) and basal plane SFs near the surface caused by polishing (Fig. 1(b)) were found. The polishing-induced defects penetrate to $\sim 120 \mathrm{~nm}$ and therefore the thickness of the damage layer is three times deeper than in the undoped samples treated in a similar way. It is expected that doping can result in a higher defect density, since calculations have shown that the formation energy of $\mathrm{SFs}$ in GaN reduces with increasing impurity concentration. ${ }^{24}$ The corresponding correlation between doping by $\mathrm{Mg}$ or $\mathrm{Si}$ and the formation of SFs in GaN has also been experimentally observed. ${ }^{25-28}$

Since the penetration depth $d$ of the excitation wavelength at $266 \mathrm{~nm}$ is only about tens of $\mathrm{nm}(d=1 / \alpha$, where $\alpha$ is the GaN absorption coefficient of $\sim 2 \times 10^{5} \mathrm{~cm}^{-1}$ at $266 \mathrm{~nm}$ (Ref. 29)), the NBG PL of GaN substrates depends strongly on the surface recombination and, thus, is not the best technique to study GaN substrates. Therefore in the following, we will discuss emissions in the C-doped GaN substrates using CL measurements. Here, we note that in the

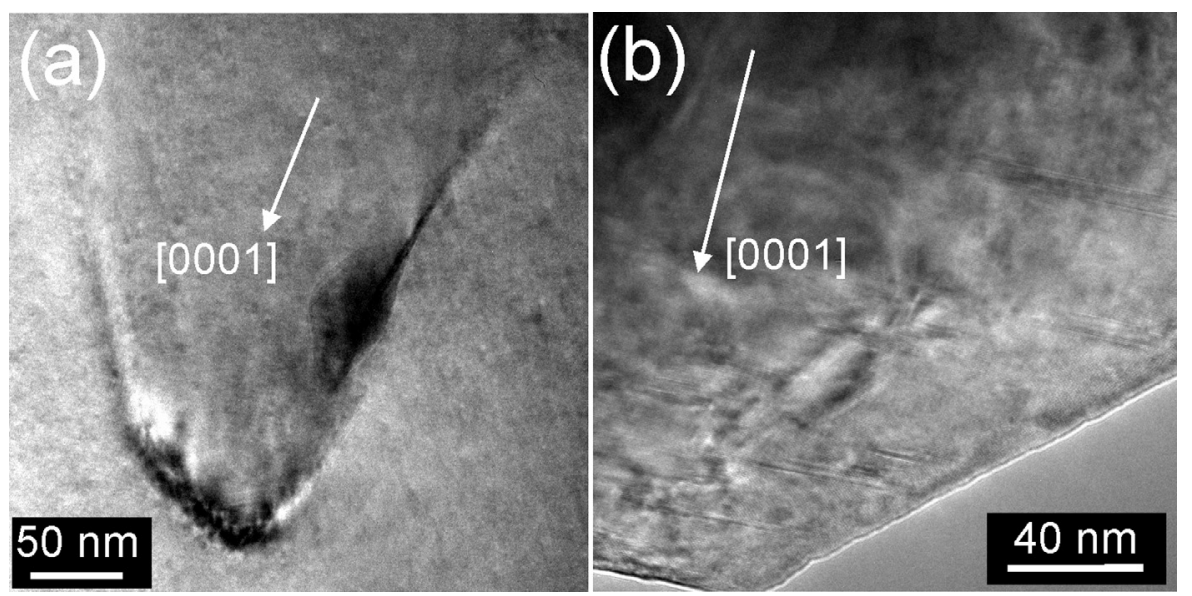

FIG. 1. (a) TEM image of a dislocation loop. (b) A number of basal plane SFs in the near-surface region. The growth direction [0001] is indicated by white arrows. 
C-doped GaN samples, the line width was broader and the PL recombination time was shorter as compared with the undoped bulk GaN substrates polished in the same way. Fig. 2 shows PL decay curves (solid lines) taken at the peak energies for the C-doped $\left(2 \times 10^{17} \mathrm{~cm}^{-3}\right)$ and undoped sample. Time-integrated PL spectra taken in the NBG region are presented in the inset for both samples. Since the measurements were done at $5 \mathrm{~K}$, the peak position at $\sim 3.480 \mathrm{eV}$ for the C-doped $\mathrm{GaN}$ is likely related to excitons bound to impurities, likely to the donor bound exciton (DBE), which has peak energy at $3.473 \mathrm{eV}$ in the undoped samples. ${ }^{30}$ The full width at half maximum (FWHM) of the PL band for the $\mathrm{GaN}: \mathrm{C}$ substrate exceeds $50 \mathrm{meV}$ in difference of undoped substrates with a FWHM of the DBE emission of $\sim 10 \mathrm{meV}$. The PL lifetime $\tau$ was extracted using a simple exponential decay law $I=I_{0} \exp (-t / \tau)$. The fitting is shown by thick dashed lines in Fig. 2. The value of $\tau=\sim 80$ ps for the Cdoped versus 220 ps for the undoped GaN substrate though obtained at $5 \mathrm{~K}$ can hardly be related to the DBE radiative lifetime and is mainly determined by a significant contribution from non-radiative surface recombination. ${ }^{31}$

To avoid influence of the near surface defects, we have used low temperature $\mathrm{CL}$ to study luminescence properties of C-doped $\mathrm{GaN}$ wafers. CL spectra measured at $5 \mathrm{~K}$ are shown in Fig. 3(a) for the undoped and C-doped samples. C concentrations are indicated for each spectrum. Upon doping, both near band gap CL and defect luminescence (or YL) are changing. For carbon concentrations in the range of $1-2 \times$ $10^{17} \mathrm{~cm}^{-3}$, the UV luminescence at $3.2-3.5 \mathrm{eV}$ depends on the point chosen at the sample surface. This is illustrated by solid and dashed lines for GaN with $[\mathrm{C}]=2 \times 10^{17} \mathrm{~cm}^{-3}$ and will be discussed later. One can see a correlation between C-doping and increasing YL at $\sim 2.2 \mathrm{eV}$. For the most highly doped wafer, we have observed broadening and high energy shift of the YL spectra, likely due to appearance of a blue emission at $\sim 2.75 \mathrm{eV}$, which is in line with previous

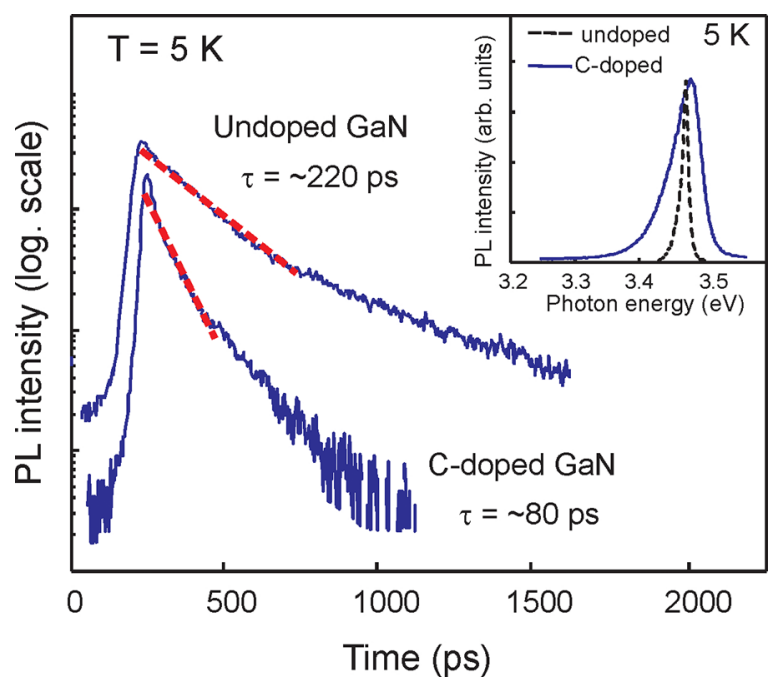

FIG. 2. TRPL spectra from C-doped ([C] $\left.=2 \times 10^{17} \mathrm{~cm}^{-3}\right)$ and undoped $\mathrm{GaN}$ with shorter decay time for the $\mathrm{C}$-doped sample indicating larger input from the nonradiative surface recombination. Inset: time integrated PL spectra from the same samples showing broader linewidth for $\mathrm{C}$-doped sample $(\sim 50 \mathrm{meV})$ compared with undoped sample $(\sim 10 \mathrm{meV})$. Fitting using single exponential decay law is shown by thick dashed lines. studies. ${ }^{7,8,21}$ For that sample, the near-band gap CL was very weak. The YL is stable in the range of $5-300 \mathrm{~K}$ and dominates $\mathrm{CL}$ at room temperature as shown in Fig. 3(b), confirming that it is related to recombination of deep defects like, for example, $\mathrm{C}_{\mathrm{N}}-\mathrm{O}_{\mathrm{N}}$ complexes, as suggested recently. ${ }^{32}$

As mentioned, we focus on the excitonic luminescence transformation upon C-doping. The $\mathrm{CL}$ spectra in the near band gap region are shown in Fig. 4 for samples with $\mathrm{C}$ concentration of $5 \times 10^{16} \mathrm{~cm}^{-3}$ and $1 \times 10^{17} \mathrm{~cm}^{-3}$, respectively. Also, the CL spectrum for the undoped sample is plotted for reference. At low temperatures, the luminescence in undoped bulk GaN is dominated by DBE line. ${ }^{28}$ With increasing C-doping, acceptor bound exciton (ABE) emission appears, while the DBE recombination is quenching. For the GaN sample with $\mathrm{C}$ concentration of $1 \times 10^{17} \mathrm{~cm}^{-3}$, two lines similar to the acceptor bound exciton emissions (ABE1 at $\sim 3.45 \mathrm{eV}$ and $\mathrm{ABE} 2$ at $\sim 3.47 \mathrm{eV}$ ) can be clearly detected together with donor-acceptor pair recombination (DAP) accompanied by LO-phonon replicas. The same spectra have been previously reported for the Mg-doped $\mathrm{GaN}$ samples with average $\mathrm{Mg}$ concentration in the range of $5 \times 10^{18}-1 \times 10^{19} \mathrm{~cm}^{-3}, 33,34$ where $\mathrm{ABE} 1$ and $\mathrm{ABE} 2$ lines correlate to acceptors involving the $\mathrm{Mg}$ atom. Thus, the appearance of two ABE lines in the C-doped GaN samples (taking into account that according to SIMS Mg concentrations are below the detection limit of $\sim 10^{15} \mathrm{~cm}^{-3}$ ) is interesting.

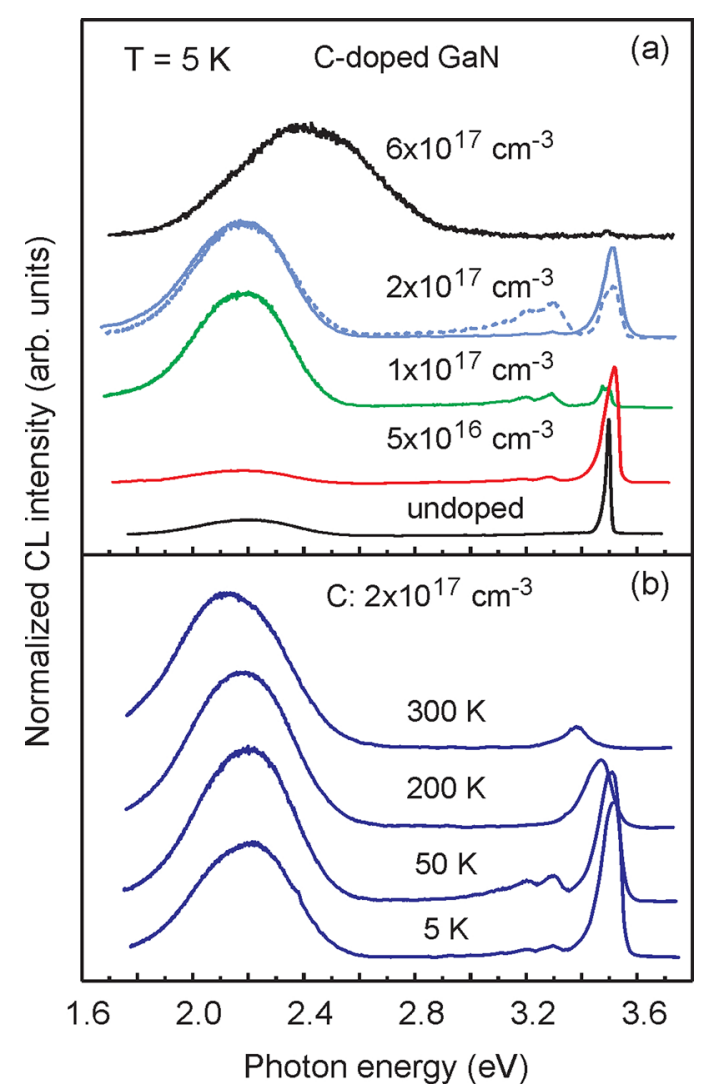

FIG. 3. (a) CL spectra from C-doped GaN samples with increasing $\mathrm{C}$ doping and a spectrum from an undoped sample for comparison. The doping is not uniform over the wafer with 2 in. diameter as illustrated for the GaN sample with $\mathrm{C}$ concentration of $2 \times 10^{17} \mathrm{~cm}^{-3}$, where the solid and dashed lines represent CL spectra taken at two different places. (b) CL spectra from $\mathrm{GaN}$ :C sample with $[\mathrm{C}]=2 \times 10^{17} \mathrm{~cm}^{-3}$ taken at different temperatures. 


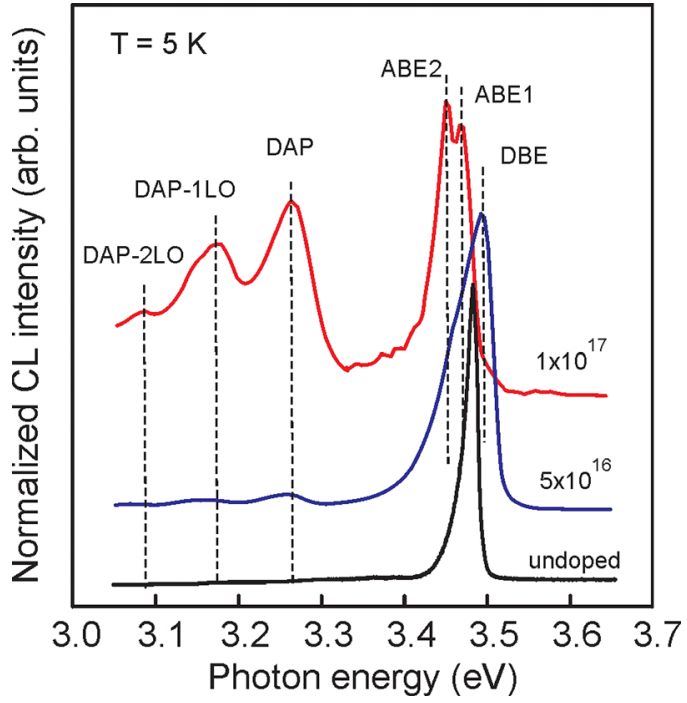

FIG. 4. CL spectra from the NBG region of the C-doped GaN samples with $\mathrm{C}$ concentrations of $5 \times 10^{16}$ and $1 \times 10^{17} \mathrm{~cm}^{-3}$. CL spectrum for the undoped bulk GaN sample is also shown for reference.

Before further discussing these results, we note that HVPE GaN bulk substrates have a domain structure as a result of spontaneous growth on both the [0001]-oriented crystals and on the semipolar $\{10 \overline{1} 2\}$ and/or $\{11 \overline{2} 2\}$ facets forming so-called hexagonal pits. ${ }^{35}$ After polishing, this structure is usually invisible in SEM images; however, it can be clearly detected by panchromatic CL mapping (Fig. 5(b)) taken at the same spatial position as the SEM topograph illustrated in Fig. 5(a) for a sample with average $\mathrm{C}$ concentration of $2 \times 10^{17} \mathrm{~cm}^{-3}$. The brighter contrast corresponds
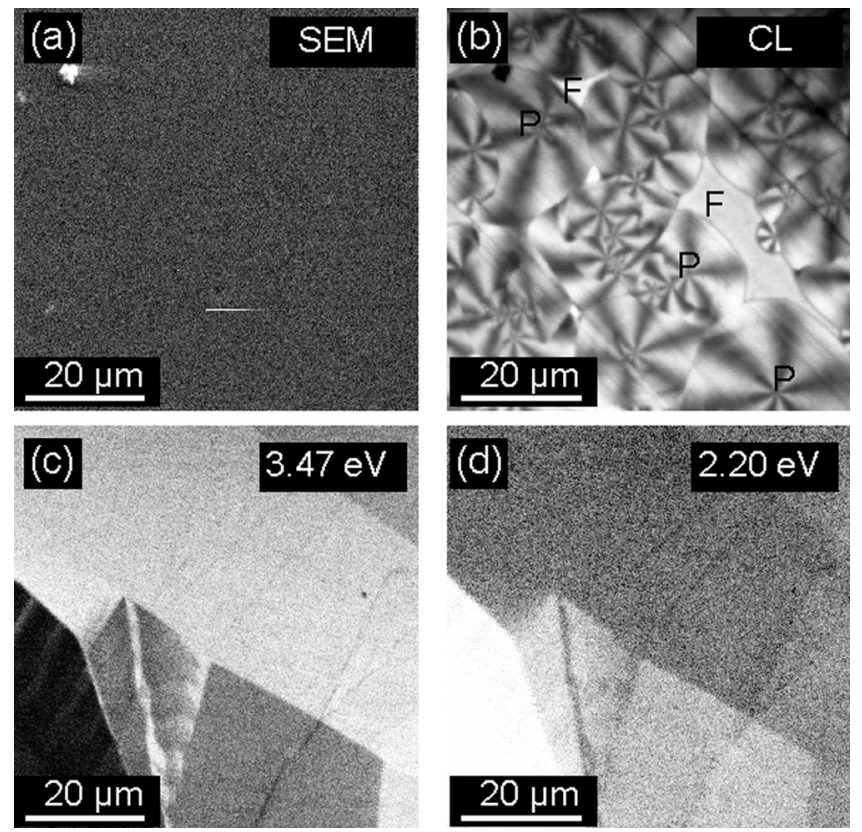

FIG. 5. (a) SEM image from the area of interest for the sample with $\mathrm{C}$ concentration of $2 \times 10^{17} \mathrm{~cm}^{-3}$. (b) Panchromatic CL image of the same place showing domain structure. (c) and (d) Monochromatic CL image taken at a different place at the energy corresponding to the DBE emission $(3.47 \mathrm{eV})$ and YL emission $(2.20 \mathrm{eV})$, respectively. In (b), regions with pits and without pits are indicated by $\mathrm{P}$ and $\mathrm{F}$, respectively. to the higher CL intensity; accordingly, the hexagonal domain pattern (in the following called pits) can be easily tracked. For clarity, we indicate in Fig. 5(b) such region by "P," while areas grown on [0001]-oriented facets by "F." The non-uniform distribution of the CL signal is caused by a selective incorporation of impurities and dopants at planes with different crystallographic orientations during the growth on the facetted surfaces. Previously, it was shown that the $\mathrm{Si}$ concentration is less sensitive to the plane orientation, while for $\mathrm{O}$ the highest concentration can be achieved in (10 $\overline{1} 1)$ and $(11 \overline{2} 2)$ oriented planes, ${ }^{36}$ which correlates with our SIMS data. Also an increased concentration of $\mathrm{C}$ was observed in the (0001) or (1011) planes though partly depending on the growth conditions. ${ }^{36} \mathrm{We}$ have observed that a high near band gap CL signal corresponds to a lower signal for the $2.2 \mathrm{eV}$ emission and vice versa as illustrated by monochromatic CL images taken at the peak energy of the bound exciton $(3.47 \mathrm{eV})$ and at the maximum of YL $(2.2 \mathrm{eV})$ shown in Figs. 5(c) and 5(d), respectively. Judging from these results, YL is stronger within the hexagonal pit domains, i.e., for growth in the lower symmetry axis planes. In assumption that YL originates from the complexes mainly involving oxygen and carbon, the results are in line with the fact that incorporation of the aforementioned impurities (at least oxygen) is more favorable at the semipolar facets.

To further investigate the appearance of two ABE related lines in $\mathrm{C}$-doped $\mathrm{GaN}$, the near band gap CL spectra have been studied with spatial resolution, i.e., depending on electron beam position. An SEM image of the chosen region together with corresponding monochromatic CL maps measured at energies of bound excitons, DAP emission and YL are shown in Figs. 6(a)-6(d) for the GaN sample with a moderate $\mathrm{C}$ concentration of $1 \times 10^{17} \mathrm{~cm}^{-3}$. Characteristic points were selected within and outside the pits as indicated in Fig. 6(b): 1, at the bright contrast area; 2 , at the place with both dark and bright contrasts; and finally, 3 , at the dark contrast area, corresponding to region with growth on the (0001) plane. The CL spectra for each place are collected in Fig. 6(e). Due to a high concentration of $\mathrm{O}$ impurities in the region of pits (point 1 ), the spectra are broadened and bound exciton related lines cannot be resolved. The CL spectrum at point 2 has also a contribution from the pit area and demonstrates three well-resolved lines related to DBE, ABE1, and ABE2. Finally, only two lines related to acceptor bound excitons (ABE1 at $3.467 \mathrm{eV}$ and $\mathrm{ABE} 2$ at $3.455 \mathrm{eV}$ ) can be observed in the area without pits (point 3). Judging from the monochromatic CL image in Fig. 6(c), the DAP emission is rather uniform. Since it is related to the recombination of shallow donors $(\mathrm{Si})$ and acceptors $(\mathrm{Mg})^{37}$ and is determined by the number of minority dopant atoms, i.e., $\mathrm{Mg}$, the background concentration of $\mathrm{Mg}$ is also uniform.

Considering results of CL data and SIMS measurements, we can conclude that (i) $\mathrm{O}$ concentrations are higher inside the pits, while it is unclear if the distribution of $\mathrm{C}$ is homogeneous or heterogeneous; (ii) the residual $\mathrm{Mg}$ concentration has a rather uniform distribution over all regions, however, it is low ( $<10^{15} \mathrm{~cm}^{-3}$ according to SIMS); (iii) with increasing the average $\mathrm{C}$ doping up to moderate values $\left(\sim 1-2 \times 10^{17}\right.$ $\mathrm{cm}^{-3}$ ), a quenching of the DBE related line has been observed 

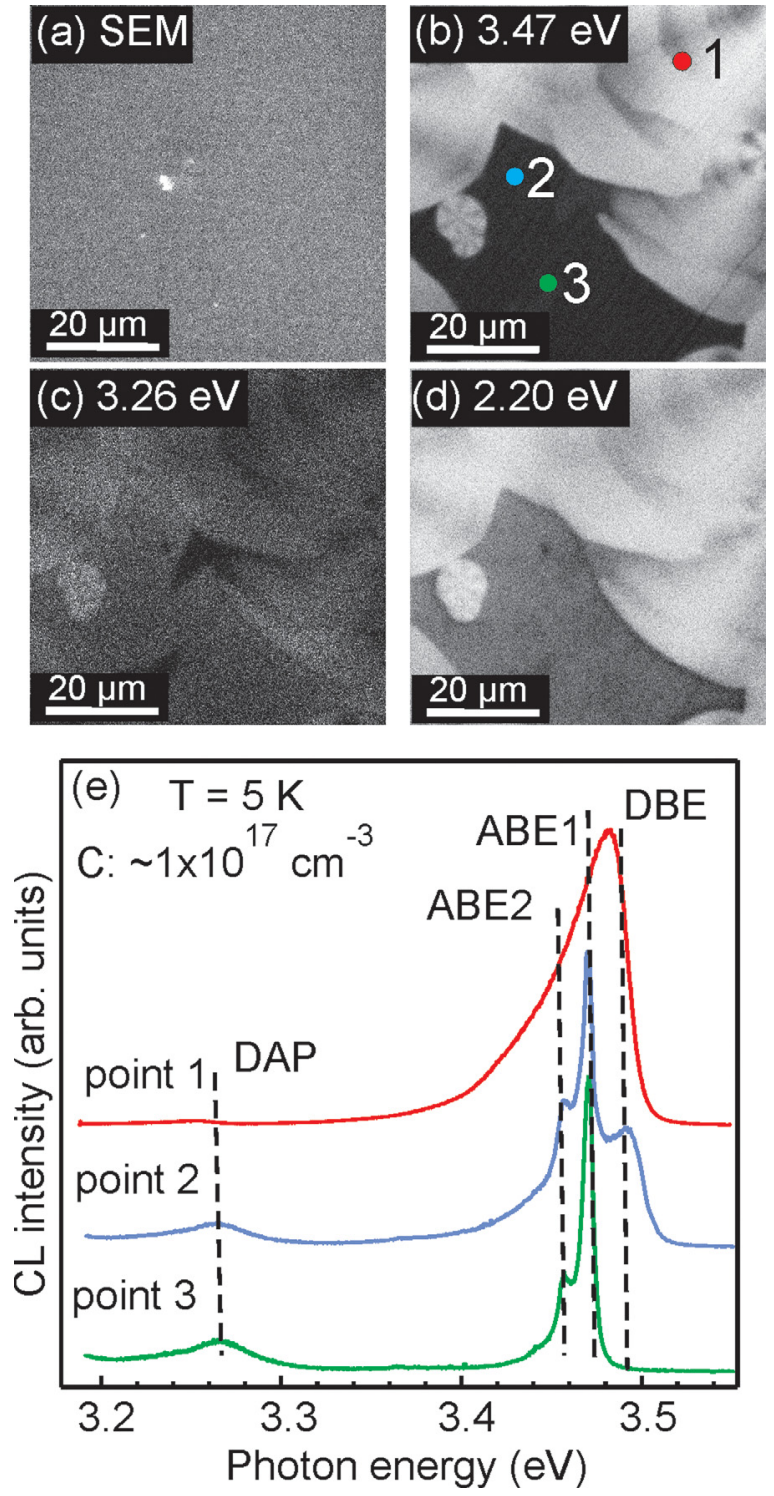

FIG. 6. (a) SEM map from an area of interest for the GaN doped by $\mathrm{C}$ with concentration of sample $1 \times 10^{17} \mathrm{~cm}^{-3}$. (b)-(d) Monochromatic CL images taken at the energy corresponding to DBE emission, DAP emission, and YL band, respectively. (e) CL spectra recorded at points indicated by numbers $1-3$ in (b)

in the areas without pits; instead, two emissions related to the acceptor bound excitons (i.e., ABE1 and ABE2) and the DAP band have been enhanced. The later spectrum is typical for the Mg-doped GaN.

The vanishing of the DBE line with increasing C-doping is in agreement with a decrease in the relative DBE intensity in more compensated GaN showing reduced room temperature Hall mobility reported previously. ${ }^{38}$ The observation of two lines similar to Mg-related ABE1 and ABE2 transitions instead of the DBE emission can be simply explained by the exciton transfer from the donors to the acceptors. However, such transfer has to be faster than the DBE lifetime and requires a high $\mathrm{Mg}$ concentration of $\sim 10^{18} \mathrm{~cm}^{-3}$ as we have seen in the case of intentionally $\mathrm{Mg}$ doped $\mathrm{GaN} .^{25,33,34} \mathrm{As}$ aforementioned, in our bulk GaN samples, $\mathrm{Mg}$ concentration is much lower, below the detection limit. On the other hand, the $\mathrm{ABE}$ lines can be observed in luminescence even at low
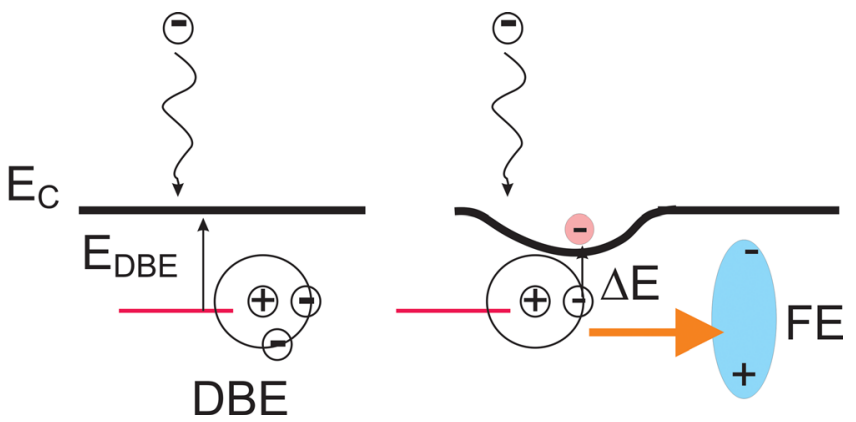

FIG. 7. Model for the DBE ionization process. On the left: in the $n$-type material, the ionization energy of DBE is large and the energy of the hot electrons is not enough for the DBE ionization process to occur. On the right: the presence of $\mathrm{C}$ atom makes the DBE ionization energy smaller making the ionization process possible.

concentrations of residual $\mathrm{Mg}$, if the excitons bound to neutral donors became dissociated. ${ }^{39}$ Thus, we suggest an alternative model to explain the observed phenomenon. The quenching of the DBE lines in the pit-free region (points 3) can be caused by the DBE ionization process requiring lower ionization energy than for the exciton bound to acceptors. To dissociate the bound excitons, the energy should be at least of the same order as the binding energy (i.e., $\sim 7 \mathrm{meV}$ for DBE and $\sim 12 \mathrm{meV}$ for ABE (Ref. 40)). The DBEs dissociate in bulk GaN when the applied electrical fields exceed $100 \mathrm{~V} /$ $\mathrm{cm}^{41}$ The bombarding electrons in CL can build up a charge density that will create a local electrical field. However, if the sample is conductive, the local fields will be very low since electrons are removed through the ground potential. Thus, for $n$-type $\mathrm{GaN}$, it is unlikely that such electrical field will be formed in $\mathrm{CL}$; however, in $\mathrm{C}$-doped $\mathrm{GaN}$ in semi-insulating areas (i.e., outside the pits) there can be potential fluctuations meaning that there are local electric fields large enough for the ionization of DBEs and consequently for quenching of the DBE luminescence. Fig. 7 shows schematically the unperturbed band diagram (left) and the DBE near the potential minimum (right), where the energy of hot electrons $\Delta \mathrm{E}$ can exceed the DBE binding energy, $\mathrm{E}_{\mathrm{DBE}}$. On the other hand, this energy is not enough to ionize more strongly bound $\mathrm{ABE}$ excitons. The dissociation of the DBE produces free carriers and excitons, which then can be trapped by deeper levels, specifically shallow acceptors (residual $\mathrm{Mg}$ atoms), resulting in increased relative intensity of the corresponding $\mathrm{ABE}$ lines. Exciton transfer processes may also be enhanced by the local fields. Thus, steady-state occupation of DBEs can be difficult in the compensated material outside the pits. Such a scenario is possible at moderate $\mathrm{C}$ concentrations in $\mathrm{GaN}$ corresponding to donor concentrations (i.e., $1 \sim 10^{17} \mathrm{~cm}^{-3}$ ). With increasing $\mathrm{C}$ doping, the number of deeper defects will increase and, thus, the carriers will be rather trapped by deep centers. This correlates with the observed decrease in the near band gap emission in the C-doped GaN sample with the highest concentration of $6 \times 10^{17} \mathrm{~cm}^{-3}$.

\section{CONCLUSIONS}

We have studied HVPE grown free-standing bulk GaN substrates doped by carbon at different concentrations 
between $5 \times 10^{16}$ and $6 \times 10^{17} \mathrm{~cm}^{-3}$. Due to a domain structure of the GaN substrates, the distribution of donor impurities (oxygen) was non-uniform. We have observed in CL collected over the large area the enhancement of the defect luminescence band at $2.2 \mathrm{eV}$ with increasing $\mathrm{C}$ concentrations. The NBG luminescence has been also transformed upon $\mathrm{C}$ doping. Low-temperature $\mathrm{CL}$ with spatial resolution has shown that inside the hexagonal pits, the NBG spectrum is typical for n-type GaN in all studied samples. However, in the region outside the pits, the DBE spectrum transforms to the $\mathrm{ABE}$ related lines at moderate $\mathrm{C}$ concentrations and, finally, the excitonic emission almost disappeared at the highest $\mathrm{C}$ doping level. Though the residual $\mathrm{Mg}$ concentration was below the detection limit of $10^{15} \mathrm{~cm}^{-3}$, the two $\mathrm{ABE} 1$ and $\mathrm{ABE} 2$ lines have been found to be similar to the emission observed in $\mathrm{Mg}$-doped $\mathrm{GaN}$ samples. The latter has been tentatively explained in a model where the DBE can be ruled out of radiative recombination due to ionization process in the presence of local electric fields in compensated material.

\section{ACKNOWLEDGMENTS}

This work was supported by the Swedish Research Council (VR) and the Swedish Energy Agency. The Knut and Alice Wallenberg Foundation supported our electron microscopy laboratory.

${ }^{1}$ A. F. Wright, J. Appl. Phys. 92, 2575 (2002).

${ }^{2}$ J. B. Webb, H. Tang, S. Rolfe, and J. A. Bardwell, Appl. Phys. Lett. 75, 953 (1999).

${ }^{3}$ C. Poblenz, P. Waltereit, S. Rajan, S. Heikman, U. K. Mishra, and J. S. Speck, J. Vac. Sci. Technol. B 22, 1145 (2004).

${ }^{4}$ A. Armstrong, C. Poblenz, D. S. Green, U. K. Mishra, J. S. Speck, and S. A. Ringel, Appl. Phys. Lett. 88, 082114 (2006).

${ }^{5}$ S. Fischer, C. Wetzel, E. E. Haller, and B. K. Meyer, Appl. Phys. Lett. 67, 1298 (1995).

${ }^{6}$ J. L. Lyons, A. Janotti, and C. G. Van de Walle, Appl. Phys. Lett. 97, $152108(2010)$.

${ }^{7}$ T. Ogino and M. Aoki, Jpn. J. Appl. Phys. Part 1 19, 2395 (1980).

${ }^{8}$ R. Armitage, W. Hong, Q. Yang, H. Feick, J. Gebauer, E. R. Weber, S. Hautakangas, and K. Saarinen, Appl. Phys. Lett. 82, 3457 (2003).

${ }^{9}$ K. Kuriyama, H. Kondo, and M. Okada, Solid State Commun. 119, 559 (2001).

${ }^{10}$ J. Elsner, R. Jones, M. Heggie, P. Sitch, M. Haugk, T. Frauenheim, S. Öberg, and P. Briddon, Phys. Rev. B 58, 12571 (1998).

${ }^{11}$ X. Li, P. W. Bohn, and J. J. Coleman, Appl. Phys. Lett. 75, 4049 (1999).

${ }^{12}$ H. Z. Xu, A. Bell, Z. G. Wang, Y. Okada, M. Kawabe, I. Harrison, and C. T. Foxon, J. Cryst. Growth 222, 96 (2001).

${ }^{13}$ K. Saarinen, T. Laine, S. Kuisma, J. Nissilä, P. Hautojärvi, L. Dobrzynski, J. M. Baranowski, K. Pakula, R. Stepniewski, M. Wojdak, A. Wysmolek, T. Suski, M. Leszczynski, I. Grzegory, and S. Porowski, Phys. Rev. Lett. 79, 3030 (1997).

${ }^{14}$ M. A. Reshchikov and H. Morkoc, J. Appl. Phys. 97, 061301 (2005).
${ }^{15}$ C. Hemmingsson, P. P. Paskov, G. Pozina, M. Heuken, B. Schineller, and B. Monemar, J. Cryst. Growth 300, 32 (2007).

${ }^{16}$ C. Hemmingsson and G. Pozina, J. Cryst. Growth 366, 61 (2013).

${ }^{17}$ C. Hemmingsson, B. Monemar, Y. Kumagai, and A. Koukitu, "Growth of III-nitrides with halide vapor phase epitaxy (HVPE)," in Handbook of Crystal Growth, Defects and Characterization, edited by G. Dhanaraj, K. Byrappa, V. Prasad, and M. Dudley (Springer-Verlag, Berlin, Germany, 2010).

${ }^{18}$ G. Pozina, S. Khromov, C. Hemmingsson, L. Hultman, and B. Monemar, Phys. Rev. B 84, 165213 (2011).

${ }^{19}$ J. A. Freitas, Jr., M. Gowda, J. G. Tischler, J.-H. Kim, L. Liu, and D. Hanser, J. Cryst. Growth 310, 3968 (2008).

${ }^{20}$ Y. Oshimura, K. Takeda, T. Sugiyama, M. Iwaya, S. Kamiyama, H. Amano, I. Akasaki, A. Bandoh, and T. Udagawa, Phys. Status Solidi C 7, 1974 (2010).

${ }^{21}$ A. Kakanakova-Georgieva, U. Forsberg, and E. Janzén, Phys. Status Solidi A 208, 2182 (2011).

${ }^{22}$ R. Zhang and T. F. Kuech, Appl. Phys. Lett. 72, 1611 (1998).

${ }^{23}$ C. Hemmingsson, P. P. Paskov, G. Pozina, M. Heuken, B. Schineller, and B. Monemar, Superlattice Microstruct. 40, 205 (2006).

${ }^{24}$ J. A. Chrisholm and P. D. Bristoweet, J. Cryst. Growth 230, 432 (2001).

${ }^{25}$ S. Khromov, C. G. Hemmingsson, H. Amano, B. Monemar, L. Hultman, and G. Pozina, Phys. Rev. B 84, 075324 (2011).

${ }^{26}$ G. Pozina, P. P. Paskov, J. P. Bergman, C. Hemmingsson, L. Hultman, B. Monemar, H. Amano, and I. Akasaki, Appl. Phys. Lett. 91, 221901 (2007).

${ }^{27}$ S. I. Molina, A. M. Sánchez, F. J. Pacheco, R. García, M. A. SànchezGarcía, F. J. Sánchez, and E. Calleja, Appl. Phys. Lett. 74, 3362 (1999).

${ }^{28}$ I. G. Batyrev, W. L. Sarney, T. S. Zheleva, C. Nguyen, B. M. Rice, and K. A. Jones, Phys. Status Solidi A 208, 1566 (2011).

${ }^{29}$ J. F. Muth, J. H. Lee, I. K. Shmagin, R. M. Kolbas, H. C. Casey, Jr., B. P. Keller, U. K. Mishra, and S. P. DenBaars, Appl. Phys. Lett. 71, 2572 (1997).

${ }^{30}$ G. Pozina, C. Hemmingsson, J. P. Bergman, D. Trinh, L. Hultman, and B. Monemar, Appl. Phys. Lett. 90, 221904 (2007).

${ }^{31}$ B. Monemar, P. P. Paskov, J. P. Bergman, G. Pozina, A. A. Toropov, T. V. Shubina, T. Malinauskas, and A. Usui, Phys. Rev. B 82, 235202 (2010).

${ }^{32}$ D. O. Demchenko, I. C. Diallo, and M. A. Reshchikov, Phys. Rev. Lett. 110, 087404 (2013).

${ }^{33}$ B. Monemar, P. P. Paskov, G. Pozina, C. Hemmingsson, J. P. Bergman, T. Kawashima, H. Amano, I. Akasaki, T. Paskova, S. Figge, D. Hommel, and A. Usui, Phys. Rev. Lett. 102, 235501 (2009).

${ }^{34}$ G. Pozina, C. Hemmingsson, P. P. Paskov, J. P. Bergman, B. Monemar, T. Kawashima, H. Amano, I. Akasaki, and A. Usui, Appl. Phys. Lett. 92, 151904 (2008).

${ }^{35}$ K. Motoki, T. Okahisa, S. Nakahata, N. Matsumoto, H. Kimura, H. Kasai, K. Takemoto, K. Uematsu, M. Ueno, Y. Kumagai, A. Koukitu, and H. Seki, J. Cryst. Growth 237-239, 912 (2002).

${ }^{36}$ S. C. Cruz, S. Keller, T. E. Mates, U. K. Mishra, and S. P. DenBaars, J. Cryst. Growth 311, 3817 (2009).

${ }^{37}$ B. Monemar, P. P. Paskov, G. Pozina, C. Hemmingsson, J. P. Bergman, S. Khromov, V. N. Izyumskaya, V. Avrutin, X. Li, H. Morkoç, H. Amano, M. Iwaya, and I. Akasaki, J. Appl. Phys. 115, 053507 (2014).

${ }^{38}$ I.-H. Lee, C.-R. Lee, D. C. Shin, O. Nam, and Y. Park, J. Cryst. Growth 260, $304(2004)$

${ }^{39}$ B. Monemar, P. P. Paskov, T. Paskova, J. P. Bergman, G. Pozina, W. M. Chen, P. N. Hai, I. A. Buyanova, H. Amano, and I. Akasaki, Mater. Sci. Eng., B 93, 112 (2002).

${ }^{40}$ R. Stepniewski and A. Wysmolek, Acta Phys. Pol. A 90, 681 (1996), available at http://przyrbwn.icm.edu.pl/APP/PDF/90/a090z4p08.pdf.

${ }^{41}$ D. Nelson, B. Gil, M. A. Jacobson, V. D. Kagan, N. Grandjean, B. Beaumont, J. Massies, and P. Gibart, J. Phys.: Condens. Matter 13, 7043 (2001). 